\title{
Prevalence of Trichomoniasis by PCR in Women Attending Health Screening in Korea
}

\author{
Seung-Ryong Kim ${ }^{1, \dagger}$, Jung-Hyun Kim², ${ }^{2,}$ Na-Yeong Gu², Yong-Suk Kim³, Yeon-Chul Hong ${ }^{4}$, Jae-Sook Ryu',** \\ ${ }^{1}$ Department of Obstetrics and Gynecology, Hanyang University Guri Hospital, College of Medicine, Guri 11923, Korea; ${ }^{2}$ Department of \\ Environmental Biology and Medical Parasitology, Hanyang University College of Medicine, Seoul 04763, Korea; ${ }^{3}$ Department of Biochemistry and \\ Molecular Biology, Hanyang University College of Medicine, Seoul 04763, Korea; ${ }^{4}$ Department of Parasitology, School of Medicine, Kyungpook \\ National University, Daegu 41944, Korea
}

\begin{abstract}
Trichomoniasis is the most common curable sexually-transmitted infection (STI) worldwide. There are few reports on the prevalence of Trichomonas vaginalis in Korea. The purpose of this study was to examine the prevalence of trichomoniasis by PCR in Guri city, Korea. All adult women who visited Hanyang University Guri Hospital for health screening within the National Health Care Service were invited to participate in the study, and 424 women were enrolled between March and June 2011. PCR was used to detect Trichomonas vaginalis using primers based on a repetitive sequence cloned from T. vaginalis (TV-E650). Fourteen women (3.3\%) were found to have T. vaginalis. All were over 50 , and they were significantly older on average than the 410 Trichomonas-negative women (mean ages 63.4 vs 55.3 years). It seems that $T$. vaginalis infection is not rare in women receiving health screening, especially among those over 50 .
\end{abstract}

Key words: Trichomonas vaginalis, PCR, prevalence, woman

Trichomoniasis is the most common curable sexually-transmitted infection (STI) in the world. Each year the pathogen causes an estimated 248 million new cases worldwide [1]. However, it has received much less consideration than other parasitic and sexually transmitted diseases. Increasing recognition of the sequelae of infection, including increased risk of infection with human immunodeficiency virus and adverse outcomes of pregnancy, has led to increased interest in T. vaginalis [2]. Although various methods such as wet mount, the Papanicolaou test, and culture are used to diagnose trichomoniasis, PCR is considered the most sensitive test. Following the introduction of PCR, more men were reported to be infected with T. vaginalis than considered when other diagnostic tests were used. Using PCR-ELISA of urine, Sena et al. [3] detected T. vaginalis infection in 177 (71.7\%) of the male partners of 256 women with trichomoniasis [3].

In Korea, the prevalence of trichomoniasis in women measured by multiplex PCR (Seegene, Seoul, Korea) was reported to be $2.5 \%$ among 279 asymptomatic individuals, and $2 \%$

- Received 24 February 2016, revised 22 March 2016, accepted 5 April 2016.

*Corresponding author (jsryu@hanyang.ac.kr)

${ }^{\dagger}$ S.R Kim and J.H. Kim contributed equally to this work.

(c) 2016. Korean Society for Parasitology and Tropical Medicine

This is an Open Access article distributed under the terms of the Creative Commons Attribution Non-Commercial License (http://creativecommons.org/licenses/by-nc/3.0) which permits unrestricted non-commercial use, distribution, and reproduction in any medium, provided the original work is properly cited. among 304 individuals who attended health examination centers [4,5]. Moreover, Goo et al. [6] reported 3.0\% prevalence among 621 women who visited 2 clinics in Daegu [6].

Since we have reported a prevalence of $2.4 \%$ among 249 asymptomatic women residing in Guri city tested with a self-developed PCR system 15 years ago, the current infection status in Guri city is not known [8]. We also reported a higher seropositivity rate (39.2\%) in 424 women who visited Hanyang University Guri Hospital for health screening by ELISA. This higher seropositivity made us to predict an increasing T. vaginalis infection rate compared with data from 15 years ago [7]. Therefore, the aim of this study was to examine the prevalence of trichomoniasis in women who visited Hanyang University Guri Hospital for health screening within the National Health Care Service by PCR, and to compare the present prevalence rate with that in the same area 15 years ago.

All adult women who visited Hanyang University Guri Hospital for health screening within the National Health Care Service were invited to participate in this study. All the subjects provided informed consent (IRB No. 2010-078). A total of 424 women (mean age $55.6 \pm 10.0$ years; age range $30-80$ years) were enrolled between March and June 2011. All the women had problem-directed histories taken and underwent a physical examination.

We used specimens of vaginal discharge for culture and 
PCR. A sterile cotton-tipped applicator was used to swab the vaginal discharge, and the applicator was placed in a tube containing $5 \mathrm{ml}$ of TYM medium and incubated at $37^{\circ} \mathrm{C}$ for $2-5$ days. The presence of parasites was confirmed by a microscope. For PCR, 3-5 ml of PBS was injected into the posterior vaginal fornix using a Pasteur pipette, and after pipetting the PBS several times to mix it with the vaginal discharge and it was recollected into a $15 \mathrm{ml}$ tube, centrifuged, and then the pellet was stored at $-70^{\circ} \mathrm{C}$.

For PCR, $5 \mu \mathrm{l}$ of vaginal sediment was mixed with $20 \mu \mathrm{l}$ of Gene Releaser ${ }^{\circledR}$ (BioVentures Inc., Murfreesboro, Tennessee, USA), and the mixture was boiled for $5 \mathrm{~min}$ in a microwave oven. It was then centrifuged, and $5 \mu \mathrm{l}$ of the supernatant was added to the PCR reaction mixture [9]. The primers were based on the T. vaginalis-specific repetitive DNA sequence in clone TV-E650-1 [10]. The primer sequences were: primer 1: 5' CATCCCCAАСATCTTTTTCAA $3^{\prime}$ and primer 2: $5^{\prime}$ TCCCATTCTTTTAGACCCITCA 3'.

The PCR reaction mixture contained $1 \mu \mathrm{l}$ each of the primers at $10 \mathrm{pmol} / \mu \mathrm{l}$ each, $2 \mu \mathrm{lNTPs}(2.5 \mathrm{mM}$ each), $0.1 \mu \mathrm{l} \mathrm{Taq}$ polymerase $(5 \mathrm{U} / \mu \mathrm{l}), 5 \mu \mathrm{l}$ pre-treated vaginal discharge, $2 \mu \mathrm{l}$ $10 \times$ PCR buffer, $5.2 \mu \mathrm{l} 5 \mathrm{M}$ betaine, and $3.7 \mu \mathrm{l}$ distilled water. The DNA was denatured for $5 \mathrm{~min}$ at $94^{\circ} \mathrm{C}$, followed by $40 \mathrm{cy}$ cles of $10 \mathrm{sec}$ denaturation at $98^{\circ} \mathrm{C}, 30 \mathrm{sec}$ annealing at $55^{\circ} \mathrm{C} / 52^{\circ} \mathrm{C}$, and 30 sec extension at $72^{\circ} \mathrm{C}$. To avoid product carryover, the PCR reactions were set up in an area physically separated from all activities involving amplified target sequences, thermocycling, and running of gels. To assess the sensitivity of the PCR, a suspension of T. vaginalis was counted with a he- mocytometer and the numbers of trophozoites were adjusted with PBS to 1, 5, 100, and 1,000 per PCR mixture. To confirm that the 318 bp band obtained by PCR originated from T. vaginalis, nested PCR was undertaken using primer 1: 5'ATCCCCAACAATGAACGAAG 3' and primer 2: 5'AATGTGATAGCGAAATGGGA 3', to confirm production of an 181 bp band.

The expected product of $318 \mathrm{bp}$ was obtained from as little as 1 organism (Fig. 1A), and nested PCR confirmed the $181 \mathrm{bp}$ band originated from T. vaginalis (Fig. 1C). Of the 424 outpatients, 14 yielded the $318 \mathrm{bp}$ band, and the prevalence of $T$. vaginalis obtained was 3.3\% (Fig. 1B). Our previous survey by PCR of 249 asymptomatic women who visited the same hospital for health care 15 years ago gave a positive rate of $2.4 \%$ [5]. Therefore, the rate of trichomoniasis infection in Guri city may be rising.

The age of the 424 outpatients ranged from 30 to 80 . Every positive patient was over 50 . There were 4 each in their 50 s and $60 \mathrm{~s}$, and 6 in their 70s. When the 424 patients were divided into 2 groups, women under $60(\mathrm{n}=280)$ and over 60 $(\mathrm{n}=144)$ had infection rates of $1.4 \%$ and $6.9 \%$, respectively, which were significantly different (Table 1 ). The mean age (63.4 \pm 8.7 years) of the 14 trichomoniasis patients was also significantly higher than that of the 410 trichomonad-negative women ( $55.5 \pm 9.9$ years) (Table 2$)$.

It is known that few T. vaginalis-infected persons have symptoms, especially, in the case of men. Among the 14 women with trichomoniasis, only 7 had symptoms such as dysuria, pruritus, burning sensation, dyspareunia, and postcoital bleeding. Therefore, significant numbers of asymptomatic T. vagina-
A

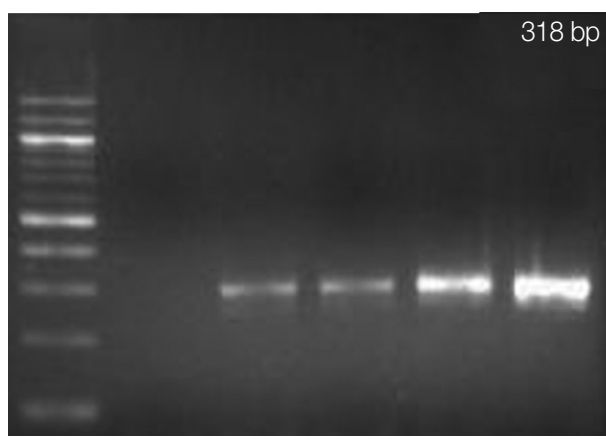

1
B

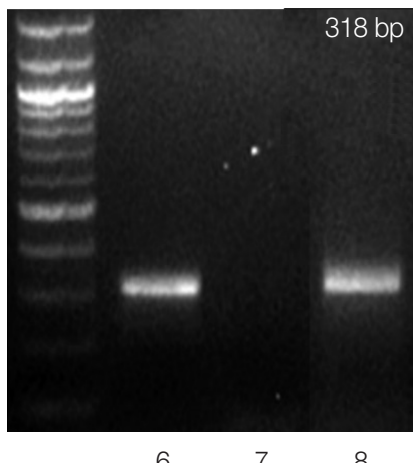

8

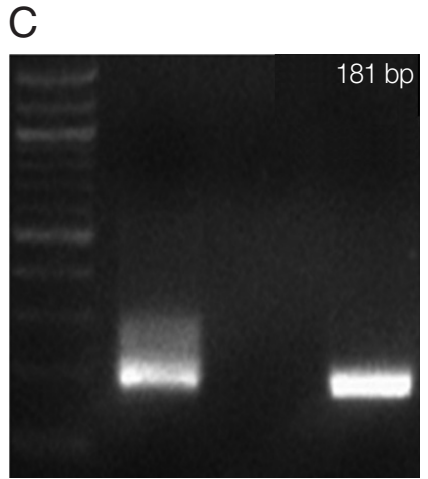

$9 \quad 10 \quad 11$

Fig. 1. Agarose gel electrophoresis of PCR products. (A) PCR using increasing numbers of trichomonads. (B) Primary PCR (318 bp) using the vaginal discharge of an outpatient with $T$. vaginalis infection. (C) Nested PCR (181 bp) done with the primary PCR product. Lane 1, distilled water; lanes 2-5, 1, 5, 100, and 1,000 trichomonads, respectively; lane 6, T. vaginalis trophozoites; lane 7, distilled water; lane 8, vaginal discharge of an outpatient with $T$. vaginalis infection; lanes 9-11, nested PCR with the primary PCR products of lanes 6-8, respectively. 
Table 1. Infection rates according to age in female outpatients

\begin{tabular}{|c|c|c|c|}
\hline \multirow{2}{*}{ Age } & \multirow{2}{*}{ No. } & \multicolumn{2}{|c|}{ No. of women showing positive result } \\
\hline & & \multicolumn{2}{|c|}{ by PCR (\%) } \\
\hline $30-39$ & 21 & $0 / 21 \quad(0.0)$ & \\
\hline $40-49$ & 98 & $0 / 98 \quad(0.0)$ & $4 / 280(1.4)^{\mathrm{a}}$ \\
\hline $50-59$ & 161 & $4 / 161 \quad(2.5)$ & \\
\hline $60-69$ & 103 & 4/103 (3.9) & \\
\hline $70-79$ & 38 & 6/38 (15.8) & $10 / 144(6.9)^{b}$ \\
\hline 80 & 3 & $0 / 3 \quad(0.0)$ & \\
\hline Total & 424 & \multicolumn{2}{|c|}{$14 / 424(3.3)$} \\
\hline
\end{tabular}

${ }^{a} v S^{b}=0.004$ by Chi-square test ( $P$-value)

Table 2. Mean ages of women giving positive and negative PCR results

\begin{tabular}{lrc}
\hline & No. & Average age $($ mean \pm S.D. $)$ \\
\hline PCR + & 14 & $63.4 \pm 8.74^{\mathrm{a}}$ \\
PCR- & 410 & $55.3 \pm 9.93^{\mathrm{b}}$ \\
Total & 424 & $55.6 \pm 10.0$ \\
\hline
\end{tabular}

${ }^{\mathrm{a}} \mathrm{VS}^{\mathrm{b}}=0.0036$ by Mann-Whitney $U$ test ( $P$-value)

lis-carrying men or women could unknowingly pass T. vaginalis to their sexual partners.

It is very interesting that the average age of the 14 infected women was over 60. In contrast, Goo et al. [6] reported that the median age of 19 infected subjects among 621 women who visited obstetrics and gynecology clinics in Daegu was 31.9 years old [6]. This age difference of the infected women probably may originate from different patient's group; target of this study was women (generally old women) who visited for health screening, while Goo et al. [6]'s subjects were younger women with genital problems who came to visit the obstetrics and gynecology clinics.

However, the increase in the prevalence of the condition with age is remarkable as it is not seen in other STDs [11]. Studies in the United States and Papua New Guinea found similar increases with age [12,13]. Moreover, Bowden et al. [11] reported a statistically significant increase in the age-specific prevalence of $T$. vaginalis but a significant decrease for Chlamydia trachomatis and human papillomavirus infections.

The increase of trichomoniasis with age may be associated with a drop in the number of lactobacilli, which are commensals of the vagina. Murta et al. [14] reported a decreased frequency of Lactobacillus species in individuals above 50 years, and lactobacilli are reported to inhibit the adhesion of T. vaginalis to host ectocervical cells [15]. In addition, in post-menopausal women, the gradual loss of glycogen and lactobacilli due to the drop in circulating estrogen may cause an increase in vaginal $\mathrm{pH}[16,17]$. Therefore, the reduction in lactobacilli and increased vaginal $\mathrm{pH}$ that occur above 50 years together may reduce the ability of women to defend against $T$. vaginalis infection. This suggestion would be helpful for understanding the higher prevalence in old women in this study.

In summary, the T. vaginalis infection rate in 424 women attending for health screening in Guri city was 3.3\%, and the rate was higher in those above 50 years old than those below 50 years. The infection rate may have increased since 15 years ago when the rate was found to be $2.4 \%$ in the same area. The use of PCR for diagnosing T. vaginalis in women over 50 years is recommended even in asymptomatic women.

\section{ACKNOWLEDGMENTS}

This research was supported by a grant from the Korea National Institute of Health, Korea Centers for Disease Control and Prevention (2011E5400600) and by a National Research Foundation of Korea (NRF) grant funded by the Korean Government (MSIP) (NRF-2014R1A2A2A01005449).

Ethical Standards: This study complied with the current laws of this country.

\section{CONFLICT OF INTEREST}

The authors declare that they have no conflicts of interest.

\section{REFERENCES}

1. World Health Organization. Prevalence and incidence of selected sexually transmitted infections, Chlamydia trachomatis, Neisseria gonorrhoeae, syphilis, and Trichomonas vaginalis: methods and results used by the WHO to generate 2005 estimates. Geneva, Switzerland. WHO, 2011.

2. Secor WE, Meites E, Starr MC, Workowski KA. Neglected parasitic infections in the United States: trichomoniasis. Am J Trop Med Hyg 2014; 90: 800-804.

3. Seña AC, Miller WC, Hobbs MM, Schwebke JR, Leone PA, Swygard H, Atashili J, Cohen MS. Trichomonas vaginalis infection in male sexual partners: implications for diagnosis, treatment, and prevention. Clin Infect Dis 2007; 44: 13-22.

4. Kim SJ, Lee DS, Lee SJ. The prevalence and clinical significance of urethritis and cervicitis in asymptomatic people by use of multiplex polymerase chain reaction. Korean J Urol 2011; 52: 703-708.

5. Lee SJ, Park DC, Lee DS, Choe HS, Cho YH. Evaluation of Seeplex $^{\circledR}$ STD6 ACE detection kit for the diagnosis of six bacterial sexually transmitted infections. J Infect Chemother 2012; 18: 
494-500.

6. Goo YK, Shin WS, Yang HW, Joo SY, Song SM, Ryu JS, Lee WM, Kong HH, Lee WK, Lee SE, Lee WJ, Chung DI, Hong Y. Prevalence of Trichomonas vaginalis in women visiting 2 obstetrics and gynecology clinics in Daegu, South Korea. Korean J Parasitol 2016; 54: 75-80.

7. Kim SR, Kim JH, Park SJ, Lee HY, Kim YS, Kim YM, Hong YC, Ryu JS. Comparison between mixed lysate antigen and $\alpha$-actinin antigen in ELISA for serodiagnosis of trichomoniasis. Parasitol Int 2015; 64: 405-407.

8. Ryu JS, Chung HL, Min DY, Cho YH, Ro YS, Kim SR. Diagnosis of trichomoniasis by polymerase chain reaction. Yonsei Med J 1999; 40: 56-60.

9. Moon HS, Lee TY, Hwang HS, Ahn MH, Ryu JS. PCR for diagnosis of male Trichomonas vaginalis infection with chronic prostatitis and urethritis. Korean J Parasitol 2012; 50: 157-159.

10. Paces J, Urbánková V, Urbánek P. Cloning and characterization of a repetitive DNA sequence specific for Trichomonas vaginalis. Mol Biochem Parasitol 1992; 54: 247-255.

11. Bowden FJ, Paterson BA, Mein J, Savage J, Fairley CK, Garland
SM, Tabrizi SN. Estimating the prevalence of Trichomonas vaginalis, Chlamydia trachomatis, Neisseria gonorrhoeae, and human papillomavirus infection in indigenous women in northern Australia. Sex Transm Infect 1999; 75: 431-434.

12. Zigas V. An evaluation of trichomoniasis in two ethnic groups in Papua New Guinea. Sex Transm Dis 1977; 4: 63-65.

13. Burch TA, Rees CW, Reardon LV. Epidemiological studies on human trichomoniasis. Am J Trop Med Hyg 1959; 8: 312-318.

14. Murta EF, Silva AO, Silva EA, Adad SJ. Frequency of infectious agents for vaginitis in non- and hysterectomized women. Arch Gynecol Obstet 2005; 273: 152-156.

15. Phukan N, Parsamand T, Brooks AE, Nguyen TN, Simoes-Barbosa A. The adherence of Trichomonas vaginalis to host ectocervical cells is influenced by lactobacilli. Sex Transm Infect 2013; 89: 455-459.

16. Lang WR. Vaginal acidity and $\mathrm{pH}$; a review. Obstet Gynecol Surv 1955; 10: 546-560.

17. Redondo-Lopez V, Cook RL, Sobel JD. Emerging role of lactobacilli in the control and maintenance of the vaginal bacterial microflora. Rev Infect Dis 1990; 12: 856-872. 